\title{
Land evaluation based on GIS for spatial management of an urbanized region, NE Iran
}

\author{
Mohammad Reza Mansouri Daneshvar \\ Department of Physical Geography, Mashhad Branch, Islamic Azad University, Mashhad, Iran
}

Email address:

mrm_daneshvar2012@yahoo.com

To cite this article:

Mohammad Reza Mansouri Daneshvar. Land Evaluation Based on GIS for Spatial Management of an Urbanized Region, NE Iran. International Journal of Environmental Protection and Policy. Vol. 2, No. 5, 2014, pp. 195-199. doi: 10.11648/j.ijepp.20140205.19

\begin{abstract}
In the present study, was used the land evaluation for spatial development of an urbanized region on the basis of analytical hierarchy process (AHP) and geographical information system (GIS). Based on this method, the surface area and percentage distribution of land evaluation were calculated and it was found that 12 landforms (about $22.5 \%$ of the surface area) are under the high and moderate suitability to spatial development. The results revealed that the regions with high suitability indices are located in the middle and south parts of the study area. In this study, was presented a map of land suitability for environmental assessment of the region, which can be applied in spatial planning, quick and safe mitigation measures and future development strategies at this urbanized region.
\end{abstract}

Keywords: Land Evaluation, Spatial Planning, Urbanized Region, AHP, GIS

\section{Introduction}

Now days the regional scale approaches in the spatial planning have been extracted in two macro attitudes of Traditional and Empirical procedures. Traditional methods such as Feng Shui Theory are the useful approaches for the ecological landscape evaluations (e.g., Mansouri Daneshvar et al., 2013), while the empirical methods are suitable for the environmental hazard assessments and spatial managements (e.g., Mansouri Daneshvar and Bagherzadeh, 2011). Several studies have developed empirical techniques for integrated spatial planning a multi-criteria decision-support tool for integrated land use planning (Recatala et al., 2000) and Relational Indicator set Model (RIM) to design a set of spatial and non-spatial indicators for the cities (Repetti and Desthieux, 2005). Other studies have also demonstrated quantitative, integrated spatial planning for achieving multiple natural resource management objectives in fields such as environmental management (Hill et al., 2005; Crossman et al., 2007), forestry (Bettinger et al., 2005), coastal areas (Bagheri et al., 2012) and agricultural resource management (Hayashi, 2000). The integration of land evaluation and GIS can provide an improved basis for addressing spatial land evaluation. Also, analytical hierarchy process (AHP) is a multi-objective and multi-criteria decision-making approach to consider at a scale of preference among a set of alternatives (Saaty, 1980; Saaty and Vargas, 2001). At the present study the hierarchy analysis for ten affecting factors as environmental indicators was used in order to find out the sustainable balance between environmental and spatial performance potential to evaluate the suitability index of 74 landforms for sustainable development at the study area.

\section{Material and Methods}

\subsection{Study Area}

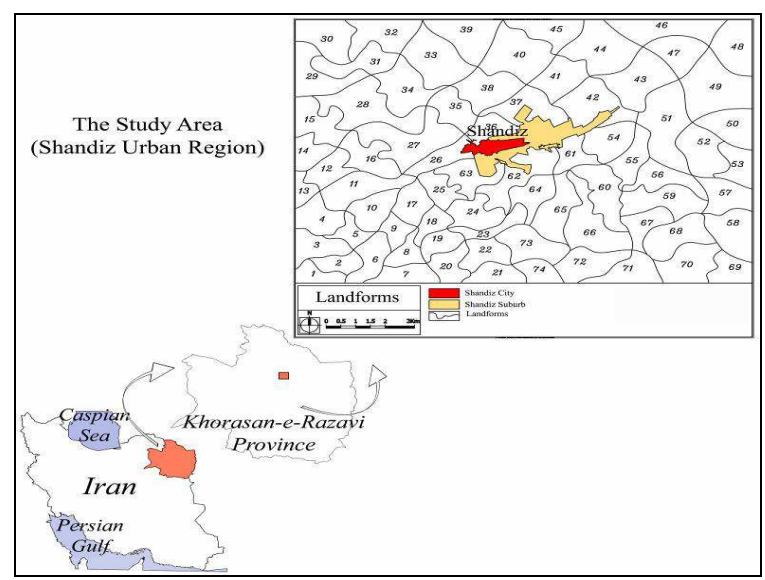

Figure 1. The geographical position of the study area, NE Iran. 
The study area includes 74 homogenous landforms around Shandiz city which are located in the northern part of Binaloud mountainous zone, Northeast Iran (Fig. 1). These landforms have been created based on topographical and hydrological features. The topographical features are complex and varied and are dominated by mountains and hills from 1000 to 1600 meter a.s.l. The study site lies between latitude $36^{\circ} 19^{\prime} \mathrm{N}$ to $36^{\circ} 26^{\prime} \mathrm{N}$ and longitude $59^{\circ} 13^{\prime}$ $\mathrm{E}$ to $59^{\circ} 23^{\prime} \mathrm{E}$ including seventy four landforms around Shandiz city with total area of about $173 \mathrm{Km}^{2}$. The study area is covered mainly by Alluvial Terraces and Phylitic formations. The area includes several fault systems at southward of Shandiz city. The main land use practices at the study area are semi-compact pasture lands and gardens. The pattern of settlements at the study area is varied between valley-villages to sprawl urbanization which are concentrated at Shandiz city. This city has been quickly developed in one decade (1999-2009) from $5.9 \mathrm{Km}^{2}$ to 13.4 $\mathrm{Km}^{2}$, while it has been populated twice as much in same time-period from 4000 to 7000 people (Mansouri Daneshvar et al., 2013).

\subsection{Methodology}

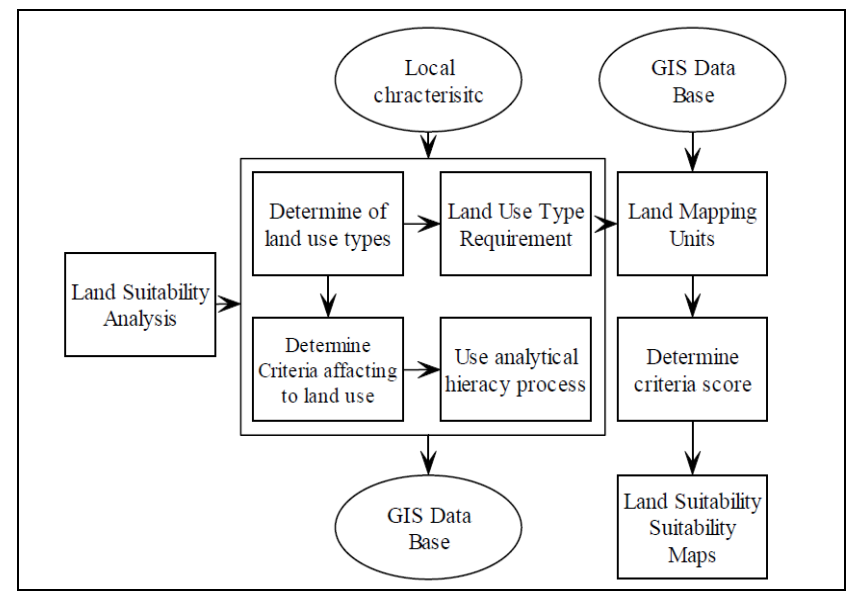

Figure 2. Spatial land evaluation process

The general process for spatial land evaluation has been extracted by Chanhda, et al., (2010) as shown in Fig 2.

Table 1. The hierarchy weight values of evaluation factors

\begin{tabular}{|c|c|c|c|c|c|c|c|c|c|c|c|}
\hline & (1) & (2) & (3) & (4) & (5) & (6) & (7) & (8) & (9) & (10) & $\mathbf{W}$ \\
\hline (1) Elevation & 1.00 & & & & & & & & & & 0.03 \\
\hline (2) Slope & 3.00 & 1.00 & & & & & & & & & 0.16 \\
\hline (3) Physical development & 6.00 & 0.33 & 1.00 & & & & & & & & 0.11 \\
\hline (4) Road network & 8.00 & 2.00 & 1.00 & 1.00 & & & & & & & 0.20 \\
\hline (5) Environmental hazards & 4.00 & 1.00 & 1.00 & 1.00 & 1.00 & & & & & & 0.16 \\
\hline (6) Vegetation & 5.00 & 0.33 & 0.50 & 0.50 & 0.50 & 1.00 & & & & & 0.10 \\
\hline (7) Drainage & 0.50 & 0.13 & 1.00 & 0.14 & 0.17 & 0.17 & 1.00 & & & & 0.03 \\
\hline (8) Geology & 3.00 & 3.00 & 1.00 & 0.33 & 0.50 & 1.00 & 3.00 & 1.00 & & & 0.11 \\
\hline (9) Soil infiltration & 1.00 & 0.20 & 1.00 & 0.25 & 0.33 & 0.25 & 3.00 & 0.33 & 1.00 & & 0.04 \\
\hline (10) Soil erosion & 5.00 & 0.25 & 0.20 & 0.33 & 0.33 & 0.50 & 3.00 & 0.50 & 3.00 & 1.00 & 0.06 \\
\hline
\end{tabular}

Consistency ratio: 0.09

Table 2. The class scores of evaluation factors.

\begin{tabular}{lll}
\hline Factors & Classes & Scores \\
\hline \multirow{2}{*}{ Elevation } & $<1400 \mathrm{~m}$ & 1 \\
\multirow{3}{*}{ Slope } & $>1400 \mathrm{~m}$ & 0 \\
& $<15 \%$ & 1 \\
Physical development & $>15 \%$ & 0 \\
& Permanent settlement & 1 \\
Road network & Non settlement & 0 \\
\multirow{5}{*}{ Environmental hazards } & Roads accessibility & 1 \\
& Non accessibility & 0 \\
Vegetation & Landslide, Flooding & 0 \\
& Non hazard & 1 \\
Drainage & Pastures, Farms & 1 \\
& Gardens & 0 \\
Geology & High drainage & 0 \\
& Low drainage & 1 \\
Soil infiltration & Sediments, Sandstone, Granite & 1 \\
& Phylitic Shale, Marl & 0 \\
Soil erosion & Low infiltration & 1 \\
& High infiltration & 0 \\
\hline \multirow{3}{*}{ Sow erosion } & 1 \\
& High erosion & 0 \\
\hline
\end{tabular}

In this process investigating and determining of spatial factor maps are essential and basic for evaluating spatial land suitability for each landform unit. Each factor requirement could be organized in form of one map layer in GIS. In this regard, about ten affecting factors including (1) Elevation, (2) Slope, (3) Physical development, (4) Road network, (5) Environmental hazards, (6) Vegetation, (7) Drainage, (8) Geology, (9) Soil infiltration, (10) Soil erosion, have been recognized, categorized and rasterized in GIS. The overlay of these map layers produces a composite map of landforms mapping. Each landform is an area which has common land-use characteristics. Different evaluation factors have different effects on land evaluation. In this regard, the analytical hierarchy process (AHP) was used and expert advice was obtained to determine the weight value of each evaluation factor. The results of the pair-wise comparison matrix for ten affecting factors have been shown in Table 1. Also, the scores of the factor classes are categorized into two levels including suitable and non suitable for the spatial development (Table 2). Then each class was given a particular score ( 0 and 1$)$ to evaluate the land evaluation. The determination of the spatial land suitability was done using the index sum method. This method sums up the product of the above mentioned factors and classes weight values for each landform by the following equation: 


$$
F=\sum_{k=1}^{n} w_{i k} \times U_{i k}
$$
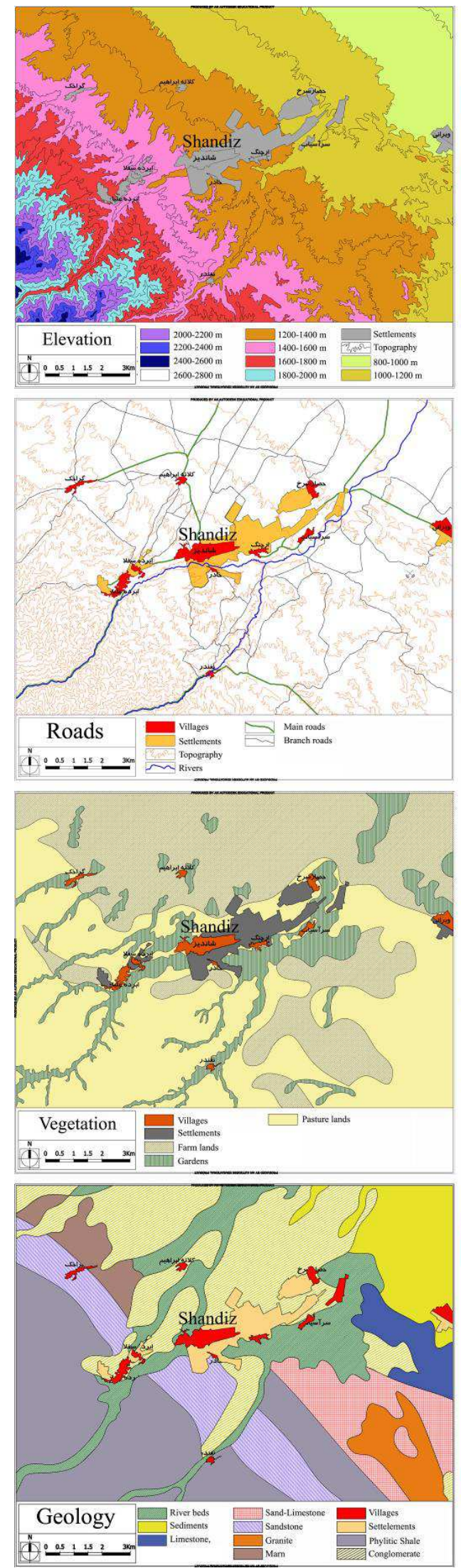
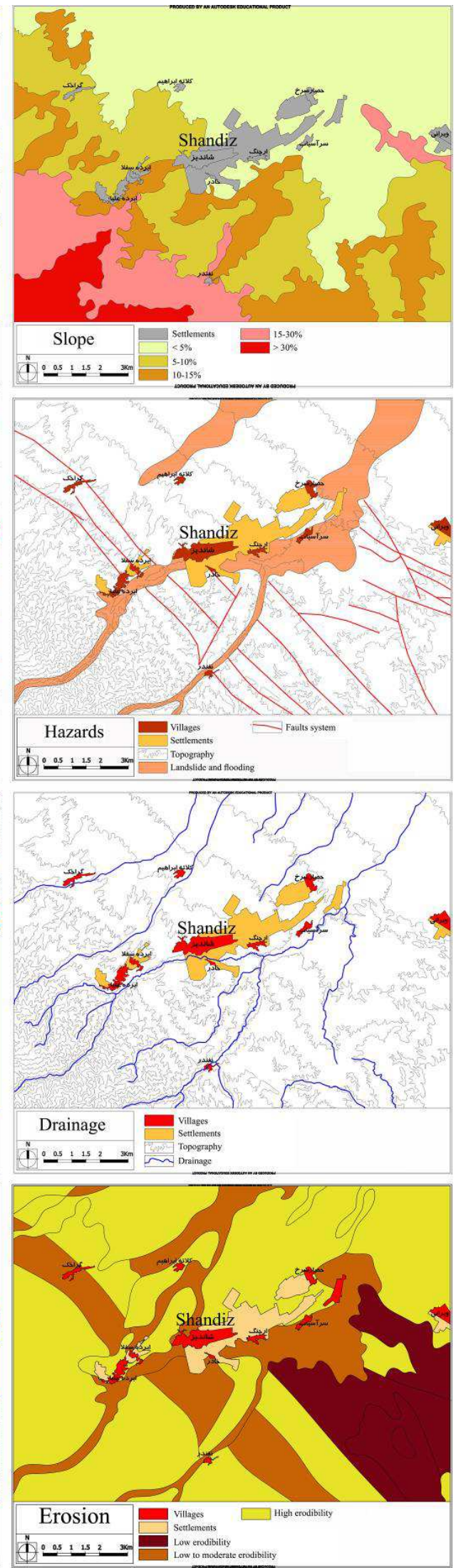

Figure 3. The affecting factor maps. 
Where $\mathrm{F}$ is the sum total of fraction values for each landform, Wik is the weight value of the $\mathrm{k}$ factor for the $\mathrm{i}$ landform, Uik is the class score of the $\mathrm{k}$ factor for the $\mathrm{i}$ landform, and $\mathrm{n}$ is the number of evaluation factors. The above-mentioned equation has been applied by Raster Calculator extension in GIS.

\section{Results and Discussion}

According to the systematic method, is presented a land suitability analysis framework for spatial development. Hence, a database is produced by digitizing the data from field observations and affecting factor maps in GIS (Fig. 3). Then the quantitative relationship between affecting factors and spatial development was achieved by the Analytical Hierarchy Process (AHP) method to produce the land suitability map. With this method, the effect of the categories of the data layer and the effect value related to each factor are quantitatively determined. It has been shown that the use of the AHP method produces a practical and realistic result to define the factor weights in the land suitability evaluation.

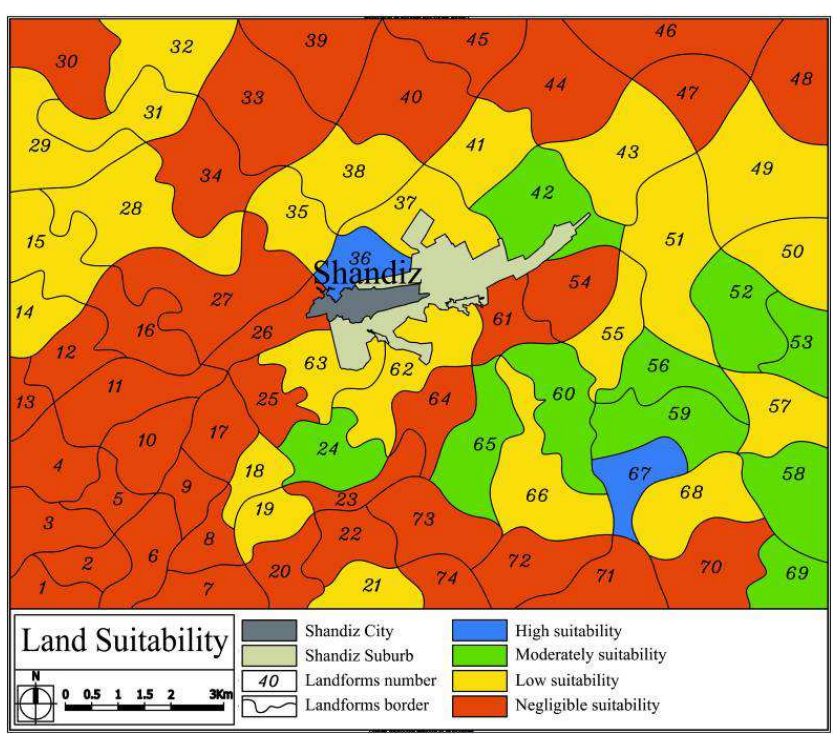

Figure 4. Land evaluation map of the study area.

Table 3. The hierarchy weight values of evaluation factors

\begin{tabular}{llll}
\hline $\begin{array}{l}\text { Land } \\
\text { suitability }\end{array}$ & $\begin{array}{l}\text { Number of } \\
\text { landforms }\end{array}$ & Area $\left(\mathbf{K m}^{\mathbf{2}}\right)$ & $\begin{array}{l}\text { \% of the study } \\
\text { area }\end{array}$ \\
\hline High & 2 & 3.4 & 2.0 \\
Moderately & 10 & 35.6 & 20.5 \\
Low & 23 & 53.8 & 31.1 \\
Negligible & 39 & 80.2 & 46.4 \\
\hline
\end{tabular}

Based on AHP method, it has been revealed that road network, slope and environmental hazard are important parameters for land suitability at the region. The resultant land evaluation map divided the study area into four zones, with suitability index of high (>0.50), moderate (0.50-0.60), low (0.60-0.70), and negligible (> 0.70) suitability (Fig 4). The area and percentage distribution of the land suitability index at the study area were determined as a result of an analysis showing the effects of each landforms (Table 3 ). According to the result of the analysis, the suitability of the study area by verbal expressions and colors is as follows; $46.4 \%$ is negligible (red), $31.1 \%$ is low (yellow), $20.5 \%$ is moderate (green) and $2.0 \%$ is high (blue). About $77.5 \%$ of the surface area including 62 landforms has a low and negligible suitability to spatial development, while about $22.5 \%$ of the surface area including 12 landforms falls into the high and moderate categories. According to land evaluation map, future spatial developments are also predicted for all areas at the middle to north that are in some proximity to slopes lower $15^{\circ}$ which corresponds well with observed pasture lands. Moderate land suitability is identified for areas comprising the gardens covered most of the hills and valleys. The results revealed the application of a systematic environmental planning approach to identify geographic priorities for spatial management at Shandiz urbanized region in accordant with Afshari and Mansouri Daneshvar (2012) and Afshari and Mafi (2014). This empirical application of land evaluation approach can be utilized with other multi-criteria decision analysis framework. GIS-based multi-criteria analysis can be thought of as a process that combines and transforms spatial data into a resultant decision (Drobne and Lisec, 2009). This method is a scientific approach to avoid errors in decision-making and spatial development of lands (Yu et al., 2009).

\section{Conclusions}

According to the results, a database is produced by digitizing the data from field observations and affecting factor maps in GIS environment. Based on AHP method, it has been revealed that road network, slope and environmental hazard are important parameters for land suitability at the region. The resultant map divided the study area into four zones, with suitability index of high, moderate, low, and negligible. The results revealed that about $22.5 \%$ of the region is prone to moderate and high suitability for spatial development. In this regard, two landforms have the high suitability to urban spatial development in future, which are located in the middle and south parts of the study area. The present study was presented a map of land suitability for environmental assessment of the region, which can be applied in spatial planning, quick and safe mitigation measures and future development strategies at this urbanized region.

\section{Acknowledgements}

I thank Islamic Azad University, Mashhad branch for its generous support of the project. 


\section{References}

[1] Afshari, M., Mafi, E. (2014) Land capability assessment for regional planning using AHP and GIS at Shandiz urban region, northeast Iran. Environment and Urbanization Asia 5: $105-118$.

[2] Afshari, M., Mansouri Daneshvar, M.R. (2012) GIS based land suitability evaluation for spatial planning using AHP method at Shandiz urban region, northeast Iran. Proceedings of the $32^{\text {th }}$ International Geography Conference, Cologne, Germany.

[3] Bagheri, M., Sulaiman, W.N.A., Vaghefi, N., (2012) Land use suitability analysis using multi criteria decision analysis method for coastal management and planning: a case study of Malaysia. Journal of Environmental Science and Technology, 5: $364-372$.

[4] Bettinger, P., Lennette, M., Johnson, K.N., Spies, T.A. (2005) A hierarchical spatial framework for forest landscape planning. Ecological Modeling 182: 25-48.

[5] Chanhda, H., Ci-fang, W.U., Yan-mei, Y.E., Ayumi, Y. (2010) GIS based land suitability assessment along Laos- China border. Journal of Forestry Research 21(3): 343-349.

[6] Crossman, N.D., Perry, L.M., Bryan, B.A., Ostendorf, B. (2007) CREDOS: a conservation reserve evaluation and design optimization system. Environmental Modeling and Software 22: 449-463.

[7] Drobne, S., Lisec A. (2009) Multi-attribute decision analysis in GIS: weighted linear combination and ordered weighted averaging. Informatica 33: 459-474

[8] Hayashi, K. (2000) Multi criteria analysis for agricultural resource management: a critical survey and future perspectives. European Journal of Operational Research 122: 486-500.

[9] Hill, M.J., Braaten, R., Veitch, S.M., Lees, B.G., Sharma, S. (2005) Multi criteria decision analysis in spatial decision support: the ASSESS analytic hierarchy process and the role of quantitative methods and spatially explicit analysis. Environmental Modeling and Software 20: 955-976.

[10] Mansouri Daneshvar, M.R., Bagherzadeh, A. (2011) Landslide hazard zonation assessment using GIS analysis at Golmakan Watershed, northeast of Iran. Frontiers of Earth Science 5(1): 70-81.

[11] Mansouri Daneshvar, M.R., Khosravi, S., Rezayi, S. (2013) Ecological evaluation of landscape using Feng-shui theory at Shandiz urban region, NE Iran. International Journal of Environmental Protection and Policy 1(2): 32-37.

[12] Recatala, L., Ive, J.R., Baird, I.A., Hamilton, N., Sanchez, J. (2000) Land use planning in the Valencian Mediterranean Region: using LUPIS to generate issue relevant plans. Journal of Environmental Management 59: 169-184.

[13] Repetti, A., Desthieux, G. (2005) A Relational Indicator set Model for urban land-use planning and management: Methodological approach and application in two case studies. Landscape and Urban Planning 77 (1-2): 196-215

[14] Saaty T.L. (1980). The analytical hierarchy process. McGraw Hill, New York, p 350.

[15] Saaty T.L., Vargas L.G. (2001) Models, methods, concepts, and applications of the analytic hierarchy process. Kluwer Academic, Boston. 333 pp.

[16] Yu, J., Chen, Y., Wu, J.P. (2009). Cellular automata and GIS based land use suitability simulation for irrigated agriculture. Proceedings of the $18^{\text {th }}$ World IMACS/MODSIM Congress, Cairns, Australia. 